\title{
OS BEBÊS E A EDUCAÇÃO INFANTIL: CONCEPÇÕES DE PEDAGOGAS EM PROCESSO DE FORMAÇÃO INICIAL
}

\author{
The babies and infantile education: conceptions of pedagogues in infantile formation \\ process
}

\author{
Los bebés y la educación infantil: concepciones de pedagogas en proceso de formación \\ inicial
}

\author{
Débora de Barros Silveira* \\ Adriana Mendonça Pizatto*
}

\begin{abstract}
Resumo
Esse artigo apresenta um estudo que teve como objetivo identificar as concepções de estudantes ingressantes no Curso de Licenciatura em Pedagogia da Universidade Estadual de Mato Grosso do Sul (UEMS), de Dourados, Mato Grosso do Sul, sobre bebês e sua educação em espaços coletivos. A importância dessa investigação é justificada na medida em que as concepções mapeadas influenciam a maneira como se organiza as práticas pedagógicas com os bebês nas instituições de educação infantil. Participaram desse estudo treze estudantes do primeiro ano do referido curso, as quais optaram por se matricular na disciplina eletiva denominada "Conhecimentos e saberes sobre as práticas com bebês na educação infantil". A coleta de dados foi feita mediante aplicação de um questionário e ocorreu no início do ano letivo. Conhecer as concepções das ingressantes no curso em relação ao trabalho pedagógico com bebês é importante, pois contribui para a reflexão sobre a formação inicial de professores na Universidade, possibilitando discussões que promovam o repensar de ideias que possam não ser adequadas à sua formação acadêmica.
\end{abstract}

PALAVRAS-CHAVE: Bebês. Educação Infantil. Formação de Professores.

\begin{abstract}
This article presents a study that had as objective to identify the conceptions of students entering the Pedagogical Degree Course of the State University of Mato Grosso do Sul (UEMS), of Dourados, Mato Grosso do Sul, about babies and their education in collective spaces. The importance of this research is justified insofar as the mapped conceptions influence the way in which the pedagogical practices are organized with the infants in the preschool institutions. Thirteen students from the first year of the course participated in this study, who opted to enroll in the elective course entitled "Knowledge and knowledge about practices with infants in early childhood education". Data collection was done through the application of a questionnaire and occurred at the beginning of the school year. Knowing the conceptions of the participants in the course in relation to the pedagogical work with infants is important, since it contributes to the reflection about the initial formation of teachers in the University, allowing discussions that promote the rethinking of ideas that may not be adequate to their academic formation.
\end{abstract}

KEYWORDS: Babies. Infantile Education. Teachers Formation.

\section{Resumen}

\footnotetext{
* Doutora em Educação pela Universidade Federal de São Carlos (UFSCar). Professora da Universidade Estadual de Mato Grosso do Sul (UEMS/Unidade Universitária de Dourados - MS). E-mail: debora@uems.br.

* Graduada em Pedagogia pela Universidade Estadual de Mato Grosso do Sul (UEMS). Professora na Escola Wings Educação Infantil. E-mail: driihmpizatto@gmail.com.
} 
Ese artículo presenta un estudio que tuvo como objetivo identificar las concepciones de estudiantes ingresantes en el Curso de Licenciatura en Pedagogía de la Universidade Estadual de Mato Grosso do Sul (UEMS), de Dourados, Mato Grosso do Sul, sobre bebés y su educación en espacios colectivos. La importancia de esa investigación es justificada en la medida en que las concepciones mapeadas influencian la manera como se organiza las prácticas pedagógicas con los bebés en las instituciones de educación infantil. Participaron de ese estudio trece estudiantes del primer año del referido curso, las cuales optaron por inscribirse en la asignatura electiva denominada "Conocimientos y saberes sobre las prácticas con bebés en la educación infantil". La recolección de datos fue hecha mediante aplicación de un cuestionario y ocurrió en el início del año lectivo. Conocer las concepciones de las ingresantes en el curso en relación al trabajo pedagógico con bebés es importante, pues contribuye para la reflexión sobre la formación inicial de profesores en la Universidad, posibilitando discusiones que promuevan el replantear de ideas que puedan no ser adecuadas a su formación académica.

PALABRAS CLAVE: Bebés. Educación Infantil. Formación de Profesores.

\section{INTRODUÇÃO}

Este artigo socializa os resultados de uma investigação realizada no âmbito do grupo de pesquisa "A criança e as instituições sociais", e que teve como objetivo identificar as concepções de estudantes ingressantes em um curso de Pedagogia sobre bebês e sua educação em espaços coletivos institucionais não domésticos ${ }^{2}$.

Investigar as concepções em questão é relevante porque essas pessoas estão iniciando um curso que tem como objetivo formar profissionais para atuar na educação infantil e, talvez seja preciso repensar algumas ideias calcadas no senso comum para construir e/ou fortalecer concepções e conhecimentos adequados para a sua formação acadêmica. As concepções que possuem sobre bebês, sua educação em ambientes coletivos não domésticos e quais experiências devem ser proporcionadas a eles, nortearão, de certa maneira, o planejamento de práticas pedagógicas instituirão em sua ação como docentes de salas de bebês. Dahlberg, Moss e Pence (2003) afirmam que a concepção de criança é considerada um aspecto-chave, uma vez que ela direciona a prática pedagógica e que esta, por sua vez, é capaz de cristalizar uma determinada imagem sobre a infância.

Colaboraram com esta pesquisa treze estudantes do Curso de Pedagogia da Universidade Estadual de Mato Grosso do Sul (UEMS), unidade universitária de Dourados, que no primeiro semestre de 2019, ao iniciarem sua formação, optaram por fazer a disciplina eletiva denominada "Conhecimentos e saberes sobre as práticas com bebês na educação infantil". Ao todo, matricularam-se na disciplina quarenta e seis discentes, das diferentes séries do curso ${ }^{3}$.

A coleta de dados foi realizada por meio de um questionário respondido pelas quarenta e uma pessoas presentes no primeiro dia de aula da disciplina e serviu para mapearmos as

\footnotetext{
${ }^{1}$ Este grupo reúne docentes e discentes da UEMS e, atua no fomento de discussões acadêmicas e políticas sobre os direitos e as necessidades da criança cidadã, bem como na organização e execução de programas de formação de professores para a educação infantil na graduação, na pós-graduação e em formação continuada.

${ }^{2}$ A pesquisa apresentada faz parte de uma pesquisa maior (em andamento), realizada pela primeira autora, denominado "Concepções de discentes do Curso de Pedagogia sobre criança e educação infantil".

${ }^{3}$ Desse total de matriculados, havia quarenta e cinco mulheres e um homem. Vinte eram ingressantes no curso, portanto, cursando o primeiro ano do curso; dezessete estavam cursando o segundo ano; sete pessoas cursavam o terceiro ano; e duas cursavam o quarto e último ano do curso. Essa mesma disciplina foi ofertada no ano de 2017, de modo que muitas alunas que cursavam o terceiro e o quarto ano do curso já tiveram a oportunidade de participar da disciplina.
} 
concepções iniciais das estudantes que se matricularam nessa disciplina eletiva. $\mathrm{O}$ questionário também fez parte das práticas pedagógicas da primeira autora, como um instrumento didático que visou gerar reflexões sobre formação inicial de professores.

O questionário pode ser conceituado como um instrumento de coleta de dados composto por algumas indagações "apresentadas por escrito às pessoas, tendo por objetivo o conhecimento de opiniões, crenças, sentimentos, interesses, expectativas, situações vivenciadas, etc." (GIL, 1999, p. 128).

A proposta da pesquisa foi apresentada aos presentes na sala de aula, na oportunidade da coleta dos dados. Destacamos os objetivos e esclarecemos que a participação seria voluntária, não havendo nenhuma implicação negativa aos que optassem pela não adesão à pesquisa. Em seguida, entregamos um Termo de Consentimento Livre e Esclarecido que foi assinado por trinta e quatro pessoas que se voluntariaram a responder o questionário e o cederam para compor o banco de dados de pesquisa. Desse total, treze pessoas pertenciam ao primeiro ano e se tornaram colaboradoras do estudo ora apresentado, sendo doze mulheres e um homem, motivo pelo qual optamos pelo emprego do gênero feminino para nos referirmos às pessoas que colaboraram com o estudo.

O questionário utilizado para a coleta de dados continha cinco perguntas objetivas para traçar o perfil das colaboradoras, quatro questões dissertativas e uma questão de associação livre mediante a proposição de uma palavra indutora, a saber, a expressão "bebê".

À época da coleta de dados, as colaboradoras possuíam idades variadas entre 17 a 32 anos, tendo nove delas idade entre 17 a 23 anos. Doze não possuíam filhos e uma era mãe de duas crianças, com idades de quatro e seis anos.

Em relação à escolaridade pregressa desse grupo, dentre as treze colaboradoras, sete delas afirmaram terem frequentado a educação infantil, sendo que duas passaram pela creche e cinco ingressaram na pré-escola, enquanto seis não frequentaram essa primeira etapa educativa.

Também foi questionado se já haviam atuado anteriormente na área da educação, mais especificamente, na educação infantil. Dentre as colaboradoras, nove responderam que não e quatro afirmaram que sim. Destas, duas afirmaram que atuam ou atuaram na pré-escola e duas na fase denominada creche, sendo que uma delas mencionou que atuava há um mês como estagiária em uma sala de bebês, no denominado Estágio Supervisionado Não Obrigatório.

Para uma aproximação ao objetivo anunciado o texto foi divido em duas partes, além desta Introdução e das Considerações Finais. Na primeira parte, em diálogo com produções científicas, tratamos sobre a educação de bebês em ambientes coletivos não domésticos e a formação de profissionais para atuar junto a eles nesses estabelecimentos de educação infantil. $\mathrm{Na}$ segunda parte apresentamos os resultados da pesquisa, explicitando as concepções das estudantes ingressantes no curso de Pedagogia da UEMS sobre bebês e outros aspectos que envolvem o seu atendimento na educação infantil.

\section{Os bebês, a educação infantil e a formação de professores}

O reconhecimento da educação infantil como etapa educativa e direito das crianças, de suas famílias e dever do Estado se deu a partir da Constituição Federal do Brasil, em 1988 (BRASIL, 1988). Para que a educação de bebês e crianças pequenas fosse reconhecida como um direito delas e de suas famílias houve, no período final da Ditadura Militar, e durante os primeiros anos de redemocratização do Brasil, intensa participação popular nos processos de elaboração e votação da Constituição. Tebet e Abramowicz (2010) destacam a ação dos 
Clubes de Mães, das Associações de Mulheres e do Movimento de Lutas por Creches, criados em 1979 durante o I Congresso da Mulher Paulista, como movimentos importantes para essas conquistas.

Com a Lei de Diretrizes e Bases da Educação Nacional, lei $\mathrm{n}^{\circ}$ 9.394, de 20 de dezembro de 1996 - LDB (BRASIL, 1996), a educação infantil foi reconhecida como a primeira etapa da Educação Básica. Desta forma, passou a abranger crianças de zero a cinco anos de idade, sendo denominado de creche o atendimento de crianças de zero a três anos e de pré-escola aquele voltado a crianças de quatro a cinco anos de idade.

Antes da Constituição Federal de 1988 e da LDB, embora não houvesse legislação que garantisse a oferta de atendimento aos bebês ou às crianças em idade de frequentar as creches, existiam iniciativas em diversos municípios, cujos atendimentos vinculavam-se à filantropia, à iniciativa privada ou ao poder público. Porém, "as ações do poder público se configuravam como políticas de amparo à maternidade e à infância, em geral, no âmbito das divisões ou secretarias de Assistência Social" (TEBET; ABRAMOWICZ, 2010, p. 57).

Até meados da década de 1990, a vinculação das creches aos órgãos da assistência social provocou uma inércia em relação à produção de pesquisas sobre educação de crianças de zere a três anos de idade em espaços coletivos. Além disso, os cursos de formação inicial ou continuada de professores não tinham preocupação com discussões sobre essas temáticas e as pessoas que atuavam em creches geralmente eram voluntárias e não possuíam formação específica. A chamada "docência na sala de bebês" ou a exigência de formação docente para atuar com as crianças em creches ocorreu somente com a LDB de 1996. Ao estabelecer que a educação de bebês em espaços coletivos faz parte da Educação Básica e que todo professor ou professora, para atuar nesse segmento, deve ter formação específica em cursos de Pedagogia ou curso normal, a legislação provocou uma mudança no perfil dos profissionais e muitos cursos de formação inicial passaram a reformular seus projetos pedagógicos.

A partir desse período algumas discussões foram intensificadas, embates e/ou reflexões sobre qual o perfil e quais conhecimentos professoras e professores precisam ter para atender as necessidades e os desafios colocados pelo atendimento de bebês e crianças pequenas em espaços de educação coletiva, em espaços públicos e não domésticos.

Considerando que foi somente a partir de 1988 que a educação infantil, em especial, a creche, foi incorporada ao sistema educacional brasileiro, parece razoável termos debates e embates sobre qual é a identidade e a função desse segmento educativo. Na perspectiva de constituir uma identidade ao atendimento de crianças pequenas, a LDB trouxe também algumas determinações, enfatizando que a educação infantil tem como objetivo promover o desenvolvimento integral das crianças e a função indissociável de cuidar e educar. Porém, mesmo depois de mais de vinte anos da existência dessa legislação, existem muitos contextos sociais e educativos em nosso país nos quais ainda se discute a função e a identidade desse atendimento educacional.

Há também vários cursos de formação de pedagogas e pedagogos nos quais ainda não há discussões sobre as especificidades das práticas pedagógicas que devem ser desenvolvidas com os bebês, existindo somente disciplinas mais gerais que abrangem a educação infantil. Há pesquisadores e pesquisadoras como Kishimoto (2011) que afirmam que a muitos anos "acumulam-se os problemas na formação, em decorrência da pouca clareza do perfil profissional desejado nos cursos de formação propostos. As contradições aparecem nos cursos amorfos que não respeitam a especificidade da educação infantil" (KISHIMOTO, 2011, p. 107). 
Outro problema apresentado pela referida autora em relação aos cursos de formação inicial é a exigência de que seus currículos deem conta de formar profissionais para todos os segmentos da educação, tais como: educação infantil, anos iniciais do ensino fundamental, gestores, educação de jovens e adultos, entre outros. Afirma também que para atender a vários propósitos, o curso dilui-se na "fragmentação disciplinar e perde a solidez" (KISHIMOTO, 2011, p. 110), tornando-se generalista e não proporcionando a compreensão sobre o saber e o fazer pedagógico.

\section{Concepções de discentes de pedagogia sobre bebês e seu atendimento na educação infantil}

\section{Perspectivas de pedagogas em início de formação sobre bebês}

Quem são os bebês? Uma indagação nada fácil de responder que foi a primeira a ser feita às treze colaboradoras do estudo. Cinco delas mencionaram que os bebês são "pequenos seres humanos ou pessoas pequenas" e, geralmente, relacionaram esta característica a uma perspectiva romântica, como amor, carinho, delicadeza, sensibilidade, entre outros. Essa perspectiva pode ser identificada na resposta de Nandinha ${ }^{4}$, que afirmou: "São pequenos seres humanos, que vem para nos dar amor e carinho". Além das respostas que continham a exaltação da característica de ser pequeno, de início da vida, relacionado à idade biológica ou cronológica, houve as que apontaram sentimentos românticos sobre os bebês, como a da colaboradora Duda: "Bebês são amor, cuidado, felicidade, unir família".

Sabemos, entretanto, que nem sempre os bebês têm este potencial de unir a família, às vezes, podem até mesmo trazer algumas dificuldades nas relações entre os adultos que o cercam, mas há uma ideia recorrente em nossa sociedade de que com os bebês se consolida a perspectiva de família ou de família nuclear, isto é, pai, mãe e filhos. Por outro lado, sabemos que os bebês são capazes de polarizar atenções ao redor de si. Talvez este possa ser o aspecto que moveu a colaboradora a afirmar que eles unem a família. Barbosa (2010) afirma que durante um longo período os bebês foram descritos pelas suas fragilidades, suas incapacidades e sua imaturidade, mas atualmente, em decorrência de pesquisas, sabemos que eles possuem muitas capacidades, "aprendemos também que os bebês são pessoas potentes no campo das relações sociais e da cognição" (BARBOSA, 2010, p. 2).

Nesse sentido, também houve respostas como a de Pink, que mencionou um contraponto ao pequeno e ao romântico e apontou que bebês são espertos e capazes de aprender com facilidade: "Bebês são minis seres humanos, delicados e sensíveis, mas muito espertos e perceptíveis, aprendem tudo com facilidade". Ver os bebês como capazes é algo importante, pois, conforme Barbosa (2010, p. 3), "Quando tomadas como seres capazes, as crianças se tornam protagonistas no projeto educacional. Essa é uma mudança paradigmática na compreensão da educação dos bebês". Vê-los como capazes é algo importante para a formação inicial de professores, pois a partir disso há a possibilidade de oferta de um atendimento educacional que promova variadas experiências e aprendizagens.

Concepções sobre bebês como pessoas em fase de desenvolvimento, como aqueles que ainda "não são, não falam, não andam" também foram pontuadas em algumas respostas. Rafa apontou que bebês "São pequenas pessoas que estão em fase de desenvolvimento que ainda não sabem como é a vida adulta" e Luna afirmou que "Bebês são crianças que ainda não sabem se defender, não consegue fazer nada sozinhos". De acordo com Didonet (2001), a

\footnotetext{
${ }^{4} \mathrm{Na}$ ocasião da coleta de dados foi sugerido às colaboradoras da pesquisa que, por motivo de sigilo, escolhessem um nome fictício para preservação de suas identidades. Também foi explicado que aquelas que desejassem poderiam preservar seu primeiro nome de registro civil ou a abreviação dele.
} 
construção do conceito de cidadania no que se refere à sua abrangência e ao seu exercício é complexa e isso se intensifica quando pensamos nas crianças pequenas, pois sobre elas recai uma dupla dominação a ser superada: física e psicológica.

A dominação física refere-se à fragilidade da criança diante do adulto, uma dependência que gera necessidade de proteção, mas também pode possibilitar a submissão e a dominação. Já a dominação psicológica refere-se ao fato de que o adulto pode ser visto como o coroamento da evolução e colocado, em nossa cultura adultocêntrica, como um parâmetro. Dessa forma, as crianças e, mais especificamente, os bebês, são vistos como "'o que vai ser', 'o que vai se desenvolver', 'aquele que ainda não...' (o que não fala, não caminha, não entende, não é capaz de, que aprende observando, experimentando e sendo ensinada...)" (DIDONET, 2001, p. 16). Vê-los com estas características como "os que ainda não" nos aponta a necessidade de um trabalho mais intenso de discussões durante o curso de formação inicial, que possibilite reflexões sobre os bebês como capazes e que já são, com todas as suas especificidades que os diferencia dos adultos.

$\mathrm{Na}$ coleta de dados também pedimos às colaboradoras para que elencassem as três primeiras palavras que se recordassem ao pensar na palavra bebês. Com base nas vinte e duas palavras evocadas, fizemos a tabulação e análise dos dados, explicitando quantas vezes cada palavra apareceu ou quais foram as que mais se repetiram nas associações das discentes. A palavra "cuidado" foi a mais citada, por seis pessoas. Em segundo lugar, a palavra "carinho", que foi mencionada quatro vezes. "Choro" apareceu três vezes. Em quarto lugar apareceram as palavras "amor", "atenção", "fraldas" e "mamar", citadas duas vezes cada.

Cuidado como o mais mencionado é interessante, pois na educação infantil cuidado e educação são indissociáveis e os bebês necessitam de um longo período de cuidados e atenção para sobreviver. Porém, é importante que o curso de formação inicial consiga tornar nítido a indissociabilidade do cuidado e educação não somente em relação aos bebês, mas a toda a faixa etária que engloba a educação infantil. Didonet (2001) salienta que a LDB de 1996 foi apropriada ao estabelecer função idêntica a creches e pré-escolas, na tentativa de superar a antiga e obsoleta dicotomia entre creche que cuida e pré-escola que educa.

\section{Concepções sobre sala de bebês}

Ao pensarem sobre o que são as salas de bebês ou os chamados berçários ${ }^{5}$ na educação infantil as trezes colaboradoras, de alguma maneira, conceituaram como espaço físico e usaram várias nomenclaturas para isso, tais como: sala (3), salinha (1), área (1), lugar (3), local (4) e a expressão onde (3), sozinha ou aliada a local. Houve resposta que se ateve a mencionar exatamente este aspecto, como a de Mia que apontou: "Eu acho que são salinhas onde ficam só os bebês por idade".

Quando optamos que na pesquisa as estudantes ingressantes escrevessem sobre sala de bebês, desejávamos conhecer suas concepções sobre bebês e sobre seu atendimento em instituições coletivas de educação. O que por elas foi apontado para além do conceito de espaço físico é muito significativo para refletirmos sobre aspectos essenciais à formação inicial de pedagogas que poderão atuar como docentes nas salas de bebês. Houve respostas que apontaram o berçário como um local de ensino ou de início da escolarização, além do

\footnotetext{
5 No questionário utilizamos a nomenclatura "berçários" por acreditarmos que as colaboradoras ouvem constantemente este nome para denominar a turma de bebês que frequentam a educação infantil em nosso município. Porém, na disciplina eletiva que estão cursando a expressão "sala de bebês" é usada na tentativa de desconstruir concepções que valorizem a existência de muitos berços nas salas das instituições, móveis estes que ocupam muito espaço e, muitas vezes, impedem movimentação mais ampla das crianças.
} 
aspecto de cuidado, tais como: "É a área da creche responsável pelo ensino e cuidado de bebês", apontada por Laura, ou de Maria Clara, que escreveu que o berçário ou sala de bebês "é o local onde as crianças iniciam sua vida escolar, esse local deve ser um ambiente tranquilo e acolhedor. Para muitos bebês esse é o primeiro local que eles ficam sem as mães e isso pode ser assustador para eles." Tais respostas evidenciam especificidades da educação dos bebês, como o cuidado, a necessidade de um ambiente tranquilo e acolhedor, o primeiro local no qual eles se distanciam de suas famílias. Entretanto, aspecto que nos alerta em relação à formação inicial de professores são os usos das palavras "ensino" e "início de escolarização" ou nas palavras da colaboradora "iniciam sua vida escolar". Ora, ressaltamos que, se não houver uma formação adequada, essas futuras professoras poderão facilmente aceitar a ideia de escolarização precoce dos bebês ou o treinamento, já inserindo-os em aprendizagens de conteúdos e não na ampliação dos conhecimentos sobre si e do mundo que os cerca.

Ao escreverem sobre bebês e educação infantil a ideia de professores e professoras com formação para atuarem na docência esteve presente em duas respostas. Porém, uma outra colaboradora trouxe a concepção de profissionais que atuam com esta faixa etária como babás. Apontou que: "São salas, que sinceramente, tem aqueles bebês, que acredito eu que algumas mães deixam com 6 meses, são escola tipo (escola de babás)" (AY). Pode-se afirmar que a colaboradora acredita que a docência na sala de bebês deve ser exercida por uma mulher, que não é necessário pensar em uma formação específica para atuar, já que muitas babás aprendem no cotidiano, não havendo o requisito de formação inicial e continuada.

A docência nas turmas de bebês exige uma formação de qualidade, pois de acordo com Barbosa (2010), adultos que trabalham na educação de bebês em espaços coletivos precisam saber ouvi-los em suas diferentes maneiras de se expressar, saber observá-los e realizar intervenções, avaliando e adequando propostas às necessidades e desejos do grupo e de cada bebê individualmente, a fim de promover aprendizagens e proporcionar desenvolvimento integral das crianças. A autora afirma também que a "profissão de professora na creche não é, como muitos acreditam, apenas a continuidade dos fazeres "maternos", mas uma construção de profissionalização que exige bem mais que competência teórica, metodológica e relacional” (BARBOSA, 2010, p. 06) ${ }^{6}$.

\section{Bebês devem frequentar a educação infantil?}

Oito colaboradoras apontaram que bebês devem frequentar espaço específico, a sala de bebês. Quatro delas apontaram que a socialização é fundamental nesta faixa etária e, por isso, devem frequentar a instituição de educação infantil. A estudante Luna afirmou que os "bebês devem ter contato com outros bebês da sua idade, ter experiências diferentes das que tem em casa, se socializar com pessoas já adultas [...]" e Maria Clara ressaltou que na educação infantil "o berçário é o primeiro ambiente onde os bebês aprendem a socializar e conviver em sociedade, sem que ele seja o único que precisa de atenção. Eu acredito que um bebê que vai para o berçário tem um maior desenvolvimento." Os aspectos citados sobre interação entre os pares, aprendizagens e desenvolvimento, são interessantes como concepções iniciais de professoras em formação.

Sobre desenvolvimento e aprendizagens dos bebês, Barbosa (2010, p. 3) afirma que "é nessa faixa etária que as interações entre as pessoas têm expressiva relevância para a construção das identidades pessoal e coletiva da criança". Ao interagir com outras crianças e com adultos, o bebê produz cultura, descobre, brinca, aprende e ensina. O brincar é atividade

\footnotetext{
${ }^{6}$ Cerisara (2002), em seu livro "Professoras de educação infantil: entre o feminino e o profissional”, apresenta os resultados de sua pesquisa junto a auxiliares e professoras que trabalhavam em creches e discute aspectos que contribuem para elucidar a construção da identidade das profissionais de educação infantil.
} 
importante para as crianças, e as instituições de educação infantil podem possibilitar muitas experiências dessa natureza favorecendo o desenvolvimento e aprendizagens, pois, "a criança não nasce sabendo brincar, ela precisa aprender, por meio das interações com outras crianças e com os adultos". (KISHIMOTO, 2010, p. 1)

Outras colaboradoras também ressaltaram que nas salas de bebês se promove o desenvolvimento e por este motivo devem frequentar uma instituição, conforme explicitado na resposta de Rachel, ao mencionar que frequentar a instituição de educação infantil é considerado "muito importante para o desenvolvimento dos bebês, não só social, como motor e cognitivo. Lá eles irão aprender a viver em sociedade e a ter a própria independência, além de perceber que existem outras crianças além deles".

As respostas acima evidenciam que nas instituições de educação coletiva deve existir um trabalho que potencialize os bebês, pois eles devem experienciar práticas significativas que contribuam para suas aprendizagens e seu desenvolvimento. Barbosa (2010, p. 05) aponta que os currículos das salas de bebês devem contemplar o desenvolvimento integral da criança, sempre por meio de práticas cotidianas, que "[...] possibilitem alargar horizontes, ampliar vivências em linguagens, para que os bebês experienciem seus saberes".

Somente Nandinha, uma das colaboradoras, mencionou que eles devem frequentar a educação infantil porque ficam sem seus pais e por isso precisam de alguém que lhes cuide, justificando que, "por passar a maior parte do tempo sem os pais por perto, eles precisam de alguém para lhe dar atenção, de alguém para brincar e para sempre estar por perto e para isso precisa amar essa área e gostar do que faz". Essa resposta nos mostra que a creche ainda tem sido compreendida com um caráter assistencialista, lugar onde as crianças ficam para serem cuidadas enquanto seus pais trabalham. Para que esta visão assistencialista seja superada, é necessário que o educador ou a educadora de bebês assuma seu papel e propicie vivências que envolvam e desenvolvam os bebês em seu aspecto integral.

Além disso, podemos observar em sua argumentação que o ou a profissional que atua nesta faixa etária ainda é visto como aquele que deve fazer por amor e, retomando seus argumentos, seria alguém que goste de estar perto, de brincar e dar atenção aos bebês. Sabemos o professor ou professora que atua na sala de bebês precisa ter afinidade com o atendimento a esta faixa etária, mas a formação, tanto inicial, como continuada, é fundamental. Para exercer a docência com os bebês é necessário ter conhecimentos, competências e habilidades que devem ser aprendidas para um bom desempenho da docência.

Fazer 'por amor' nos remete às atividades desempenhadas por mulheres em seu dia a dia no cuidado com as crianças, as relações afetivas entre mães e bebês, o trabalho doméstico de cuidados e socialização das crianças e, como afirma Kramer (2011, p. 125), essas "tarefas não são remuneradas e têm aspecto afetivo e de obrigação moral". Se perspectivarmos o trabalho na educação infantil com os bebês nesse sentido, a pouca formação profissional, os baixos salários ou a desmobilização referente às reivindicações salariais, as precárias condições de trabalho se naturalizam, pois não há uma identidade profissional valorizada.

Dentre as treze colaboradoras da pesquisa, cinco assinalaram a opção "talvez" ao responderem se os bebês devem frequentar a educação infantil e justificaram de diferentes maneiras, tais como: caso os pais precisem trabalhar, se os pais não têm como cuidar, frequentar somente quando estiverem maiores e já souberem andar e não frequentar pela necessidade de cuidados serem realizados pela mãe e a necessidade de contato com a mãe.

\footnotetext{
${ }^{7}$ É bem possível que o próprio nome da disciplina eletiva tenha influenciado para que nenhuma das colaboradoras da pesquisa assinalasse a opção não para a pergunta se os bebês devem frequentar a educação infantil.
} 
Essas indefinições de que se devem ou não frequentar a educação infantil associada ao trabalho ou não dos pais e a disponibilidade de um membro da família de cuidar do bebê, é mencionado por Mia, que afirmou que "[...] bebês ficam porque seus pais precisam trabalhar", e também por Rafa, que apontou: "Talvez. Porque talvez os pais não tenham como cuidar da criança e o único lugar para eles ficarem é esse". A partir dessas afirmações é possível refletir que há necessidade de discutirmos nos cursos de formação de professores que a educação infantil é um direito das crianças, que as Diretrizes Curriculares Nacionais para a Educação Infantil (DCNEI) (BRASIL, 2010) asseguram a todas as famílias o direito de solicitar vagas em creches próximas às suas residências, portanto vagas para os bebês, se assim o desejarem, sem requisito de seleção. Ora, muitas vezes não há vagas suficientes para atender a demanda, mas é importante que professoras em formação entendam que educação infantil é prevista como direito e não é um favor prestado às famílias. Assim, segundo Barbosa (2010), entre outros, a instituição de educação infantil deve ser considerada uma parceira da família.

\section{Educação de qualidade: que atividades os bebês devem realizar?}

Ao pensarem nas atividades que devem ser desenvolvidas nas salas de bebês, as colaboradoras da pesquisa apresentaram várias sugestões e, às vezes, em uma mesma resposta um conjunto de sugestões. As brincadeiras e o brincar foram os mais citados, em dez respostas. Dinda afirmou que no berçário os bebês devem realizar "brincadeiras e se socializar com outros bebês [...]". Sua afirmação vai ao encontro dos eixos norteadores das DCNEI (BRASIL, 2010), a qual indica que "as práticas pedagógicas que compõe a proposta curricular da Educação Infantil devem ter como eixos norteadores as interações e a brincadeira [...]" (BRASIL, 2010, p. 25, ênfase no original).

Kishimoto (2010) aponta que o brincar é um dos direitos das crianças, é algo que elas gostam, que "o brincar é uma ação livre, que surge a qualquer hora, iniciada e conduzida pela criança; dá prazer, não exige como condição um produto final; relaxa, envolve, ensina regras, linguagens, desenvolve habilidades e introduz a criança no mundo imaginário." (KISHIMOTO, 2010, p. 1). Desta forma, o brincar deve estar presente desde o início da educação infantil, nas salas de bebês, fazendo parte do dia a dia das crianças, pois elas estão chegando ao mundo e construindo relações (RICHTER; BARBOSA, 2010).

Outra atividade mencionada pelas colaboradoras da pesquisa foi a realização de atividades ligadas à linguagem musical. Nandinha, por exemplo, citou que o professor deve "usar a música como aprendizado para os bebês". Neste sentido, o Referencial Curricular Nacional para a Educação Infantil (RCNEI) (BRASIL, 1998) afirma que a música é uma linguagem que "proporciona o desenvolvimento da expressão, do equilíbrio, da auto-estima e autoconhecimento, além de poderoso meio de integração social" (BRASIL, 1998, p. 49). Dessa maneira, a música deve ser levada às salas de bebês em forma de brincadeiras com os ritmos, a fim de instigar o gosto pela linguagem musical, de estimular o desenvolvimento da capacidade motora, da expressão corporal e de apreciar diferentes estilos musicais.

Três colaboradoras da pesquisa afirmaram que as práticas pedagógicas devem proporcionar o desenvolvimento da coordenação motora dos bebês. Laura indicou que isso pode ser feito por meio das "brincadeiras que ajudem a desenvolver a coordenação motora". Tal concepção é interessante se for entendida na perspectiva de que os bebês são capazes, que se movimentam, que desejam, sabem e escolhem objetos e brinquedos para manipulá-los e que essas ações proporcionam a eles o desenvolvimento não apenas motor, mas integral. A estratégia pedagógica denominada de "Cesto do tesouro ou cesto de objetos", criada por Elinor Goldschmied (2006), exemplifica a perspectiva apresentada, pois ao manipular, explorar e experimentar os objetos o bebê amplia suas experiências. 
Outra colaboradora, Maria Clara, além de escrever sobre as brincadeiras, nomeou aspectos da arte como componentes importantes, tais como literatura e artes cênicas. Ela escreveu que "Os bebês podem brincar com massinha, objetos coloridos que chamem a atenção, brincar com bonecas e bolas também é interessante. Acho que deve existir um momento de leitura e teatros também". Observamos em sua resposta a presença de experiências que contemplam as denominadas "múltiplas linguagens das crianças", as quais são, a nosso ver, importantes no trabalho de qualidade nas turmas de bebês. Entendemos que "falar em diferentes linguagens é falar de busca, imaginação, fruição, liberdade de expressão, pesquisa, experiência: criança e criação não podem ser fixadas - são experimentação, com todos os sentidos" (OSTETTO, 2017, p. 64).

Fator que também perpassa a argumentação de Maria Clara é a concepção de bebê ativo, potente e capaz, e de que as atividades propostas têm o potencial de proporcionar o desenvolvimento integral da criança. Nos atendimentos aos bebês ou crianças pequenas é fundamental pensarmos que as práticas pedagógicas os atingem e devem ser planejadas e propostas num sentido que integre o aspecto físico, cognitivo, afetivo, social, que amplie suas capacidades de expressão por meio de múltiplas linguagens, pois as crianças são seres indivisíveis.

Dentre as trezes colaboradoras, uma destacou, que a seu ver, nas salas de bebês as práticas pedagógicas devem ser

\begin{abstract}
Atividades envolvidas com alguma disciplina que encontramos na escola, por exemplo matemática, onde a maioria possui dificuldade, seria da seguinte forma: sala de aula teria bonecas e bolas de futebol ou algo mais pequeno e o professor usaria das operações simples, soma, divisão, subtração e multiplicação, são simples, mais certeza que os alunos se divertiriam com isso (Luna).
\end{abstract}

Em sua resposta existem práticas conhecidas como escolarização precoce nas salas de bebês, reflexos do ensino fundamental sendo trazidos para a educação infantil. As DCNEI (BRASIL, 2010, p. 30) alertam que as práticas pedagógicas na educação infantil devem respeitar as especificidades etárias, "sem antecipação de conteúdos que serão trabalhados no Ensino Fundamental". Kishimoto (2011, p. 107), ao tratar sobre "escolarização" na educação infantil, afirma que este termo é "utilizado frequentemente por educadores da pequena infância para justificar o excesso de leitura, escrita e cálculo nas atividades infantis". A autora argumenta que a escolarização de crianças pequenas também é ocasionado por problemas relacionados a cursos de formação inicial, pois a maioria dos cursos de Pedagogia formam profissionais para atuar com crianças de 0 a 10 anos de idade, sem diferenciar formação específica para a educação infantil, portanto para a docência com crianças de 0 a 5 anos e formação para docência nos anos iniciais do ensino fundamental, para atuar com crianças de 6 a 10 anos. Nesses cursos, geralmente, a educação infantil acaba tendo um espaço formativo menor e professores concluem suas formações iniciais sem uma formação sólida que lhes permita planejar práticas pedagógicas apropriadas à docência com bebês, crianças pequenas e crianças pré-escolares.

\title{
CONSIDERAÇÕES FINAIS
}

Ao analisarmos as concepções de ingressantes do curso de Pedagogia da UEMS no primeiro semestre de 2019, em relação às suas concepções sobre bebês, o trabalho pedagógico com eles e sua frequência na instituição de educação infantil, identificamos que essas perpassam pelo lado romântico, afetuoso e pouco se fala do bebê ativo, capaz, aquele que "já é". 
Já em relação às concepções sobre os bebês frequentarem instituições de educação infantil, pudemos identificar que a maior parte das colaboradoras concordam com a estada dos bebês nesse espaço, entendendo-o como importante para o desenvolvimento integral. Porém, algumas concepções ainda revelam que a creche é vista como uma instituição de assistência aos pais que trabalham e não como uma instituição que atua em parceria com as famílias no cuidado e educação das crianças. Há também as ingressantes que acreditam que os bebês precisam estar em constante cuidado, os quais devem ser realizados tão somente pelas mães.

Outros aspectos investigados na pesquisa foram as suas perspectivas sobre as possibilidades do trabalho pedagógico com os bebês e, em suas respostas encontramos propostas que abarcam o trabalho com as múltiplas linguagens, tais como brincadeiras, movimento, música, entre outros, considerando, assim, a criança como um ser ativo no seu processo de desenvolvimento.

Destacamos a necessidade de os cursos de formação inicial abordarem com mais ênfase a educação na primeira infância, pois o trabalho nesta faixa etária necessita de propostas pedagógicas que respeitem, valorizem e estimulem o desenvolvimento e as aprendizagens das crianças.

\section{REFERENCIAS}

BARBOSA, de Maria Carmem. As especificidades da ação pedagógica com os bebês. In.: Anais do I Seminário Nacional Currículo em Movimento - Perspectivas Atuais. Belo Horizonte, novembro de 2010. Disponível em: <portal.mec.gov.br/docman/dezembro-2010pdf/7154-2-2-artigo-mec-acao-pedagogica-bebes-m-carmem/file:. Acesso em: 03 jul. 2013.

BRASIL. Constituição da República Federativa do Brasil. Brasília: Senado Federal, 1988.

BRASIL. Lei de Diretrizes e Bases da Educação Nacional. Lei Federal nº 9.394, de 20 de dezembro de 1996.

BRASIL. Ministério da Educação e do Desporto. Secretaria de Educação Fundamental. Referencial Curricular Nacional para a Educação Infantil: conhecimento de mundo. Brasília - DF, MEC/SEF, 1998.

BRASIL. Ministério da Educação. Secretária de Educação Básica. Diretrizes Curriculares Nacionais para a Educação Infantil. Brasília: MEC, SEB, 2010.

CERISARA, Ana Beatriz. Professoras de Educação Infantil: entre o feminino e o profissional. São Paulo: Cortez, 2002.

DAHLBERG, Gunilla; MOSS, Peter; PENCE, Alan. Qualidade na educação da primeira infância. Porto Alegre: Artmed, 2003.

DIDONET, Vital. Creche: a que veio... para onde vai... Em aberto. Brasília, V. 18, n. 73, 2001. p. 11- 27. Disponível em:

<http://emaberto.inep.gov.br/index.php/emaberto/article/view/2133/0>. Acesso em: 03 de jul. 2018.

GIL, Antônio Carlos. Métodos e técnicas de pesquisa social. São Paulo: Atlas, 1999.

GOLDSCHMIED, Elinor; JACKSON, Sonia. Educação de 0 a 3 anos. $\mathrm{O}$ atendimento em creche. Tradução Marlon Xavier. 2. ed. Porto Alegre: Artmed, 2006.

KISHIMOTO, Tizuko Morchida. Brinquedos e Brincadeiras na Educação Infantil. In.: Anais do I Seminário Nacional: currículo em movimento - Perspectivas Atuais. Belo Horizonte, 
novembro de 2010. Disponível em: <portal.mec.gov.br/docman/dezembro-2010-pdf/7155-23-brinquedos-brincadeiras-tizuko-morchida/file>. Acesso em: 12 de ago. 2015.

Encontros e desencontros na formação dos profissionais de educação infantil. In:

MACHADO, Maria Lucia de A. (Org.). Encontros e desencontros em educação infantil. São Paulo: Cortez, 2011. 4. ed. p. 107-115.

KRAMER, Sônia. Formação de profissionais de educação infantil: questões e tensões. In: MACHADO, Maria Lucia de A. (Org.). Encontros e desencontros em educação infantil. São Paulo: Cortez, 2011. 4.ed. p. 117-132.

OSTETTO, Luciana Esmeralda. Sobre a organização curricular da Educação Infantil: conversas com professoras a partir das Diretrizes Curriculares Nacionais. Revista Zero-a-seis, v. 19, n. 35 p. 46-68, jan./jun. 2017. Disponível em:< http://dx.doi.org/10.5007/19804512.2017v19n35p46>. Acesso em: 03 de abr. 2018.

RICHTER, Sandra Regina; BARBOSA, Maria Carmen Silveira. Os bebês interrogam o currículo: as múltiplas linguagens na creche. Revista Educação, Santa Maria, v. 35, n. 1, p. 85-96, jan./abr. 2010. Disponível em:

<https://periodicos.ufsm.br/reveducacao/article/view/1605/900>. Acesso em: 13de maio. 2018.

TEBET, Gabriela Guarnieri Campos; ABRAMOWICZ, Anete. Creches, educação infantil e políticas públicas municipais: um olhar sobre a cidade de São Carlos-Brasil. Políticas Educativas, v. 3, n.2, p. 25-39, 2010. Disponível em:

<http://www.seer.ufrgs.br/Poled/article/view/22720>. Acesso em: 03 de abr. 2018.

Recebido em: 03/05/2019

Aprovado em: 05/07/2019 